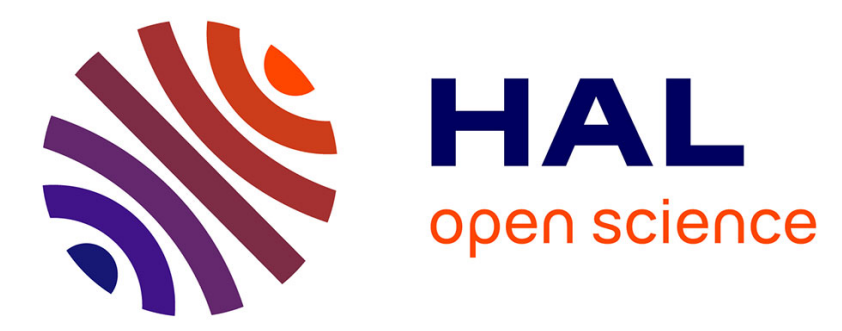

\title{
Enterprise Integration and Networking: theory and practice
}

\author{
Hervé Panetto, Ricardo Goncalves, Arturo Molina
}

\section{To cite this version:}

Hervé Panetto, Ricardo Goncalves, Arturo Molina. Enterprise Integration and Networking: theory and practice. Annual Reviews in Control, 2012, 36 (2), pp.284-290. 10.1016/j.arcontrol.2012.09.009 . hal-00733103

\section{HAL Id: hal-00733103 \\ https://hal.science/hal-00733103}

Submitted on 17 Sep 2012

HAL is a multi-disciplinary open access archive for the deposit and dissemination of scientific research documents, whether they are published or not. The documents may come from teaching and research institutions in France or abroad, or from public or private research centers.
L'archive ouverte pluridisciplinaire HAL, est destinée au dépôt et à la diffusion de documents scientifiques de niveau recherche, publiés ou non, émanant des établissements d'enseignement et de recherche français ou étrangers, des laboratoires publics ou privés. 


\title{
Enterprise Integration and Networking: theory and practice
}

\author{
Hervé Panetto*,1,2 $^{,}$Ricardo Jardim-Goncalves ${ }^{3}$, Arturo Molina**,4 \\ ${ }^{1}$ Université de Lorraine, CRAN, UMR 7039, Campus sciences \\ B.P. 70239, Vandœuvre-lès-Nancy Cedex, 54506, France \\ (e-mail: herve.panetto@univ-lorraine.fr) \\ ${ }^{2}$ CNRS, CRAN, UMR 7039, France \\ ${ }^{3} \mathrm{CTS}$, Departamento de Engenharia Electrotecnica, Faculdade de Ciencias e Tecnologia, Universidade \\ Nova de Lisboa, UNINOVA, Portugal \\ (e-mail: rg@uninova.pt) \\ ${ }^{4}$ Tecnologico de Monterrey, Mexico \\ (e-mail: armolina@itesm.mx)
}

\begin{abstract}
Research and technological developments in Enterprise Integration and Networking requires identifying achievements, challenges and trends in order to establish a set of coherent vision and roadmap for future research. This paper analysis and discusses on recent achievements and future trends on research for Enterprise Integration and Networking solutions, identifying principal challenges for this research area. Such challenges are then analysed with regard to the contributions of this special issue, organised with extended papers selected by the IFAC TC 5.3 and presented at the IFAC INCOM 2012 symposium held in Romania on May 2012.
\end{abstract}

Keywords: Enterprise Architecture, Enterprise Integration, Enterprise Interoperability, Enterprise Networking

\section{INTRODUCTION}

In the Network-driven Economy, Enterprise Integration and Enterprise Interoperability solutions co-exist with each other to achieve the true: "Networked Enterprise" ecosystem. To be successful at integrating a pool of organisations and their related support institutions in a dynamic business ecosystem, four major scientific disciplines: Enterprise Architecture, Enterprise Integration, Enterprise Interoperability and Enterprise Networking, are working in providing organisations with the suitable technical and managerial solutions to support their different forms of business collaboration. This issue of the journal focuses on presenting novel research achievements of the scientific community to breakdown the organisational and technological barriers to improve the synergy within the enterprise and among enterprises based on enterprise modelling, architectural and ontological approaches to support enterprises collaboration in networked environments.

Enterprise Integration involves breaking down organizational barriers to improve synergy within the enterprise, so that business goals are achieved in a more productive and efficient way. Collaboration is necessary for enterprises to prosper in the current extreme dynamic and heterogeneous business ecosystems. Enterprise integration, interoperability and networking are the major disciplines that have studied how to do companies to collaborate and communicate in the most effective way. These disciplines are well-established and are supported by international conferences (e.g., EI2N, I-ESA, INCOM), research groups (e.g., IFAC TC 5.3 "Enterprise Integration and Networking", IFIP TC5 "Information Technology Application"), task forces (e.g., European Commission FInES cluster) and governmental projects (e.g., many all over the world where different domains of knowledge have been considered from different points of views and towards a variety of objectives at technological, managerial and organizational levels).

The past decade of enterprise integration research and industrial implementation has seen the emergence of important new research areas, such as "interoperability" and "networking", which involve breaking down organizational barriers to improve synergy within the enterprise and among enterprises. The ambition to achieve dynamic and effective cooperation of enterprises within networks of companies requires the improvement of existing, or the development of new theories, frameworks and technologies 
embracing Enterprise Modelling, Architectures, and Semantic Interoperability principles as essential pillars supporting the achievement of Enterprise Integration and Interoperability.

Moreover, organizations wish to adapt themselves according to the market demands and the availability of new systems and applications. Adaptation brings complexity, processes, models and semantics change, where heterogeneity of applications and data is present, mostly resulting in the loss of stability of the enterprise interoperable environment through failure of harmonization. These facts introduce the new concept of "sustainable interoperability". Sustainable interoperability is a new research dimension into the interoperability of enterprise systems and applications domain that is looking for novel strategies, methods and tools to maintain and sustain the interoperability of enterprise systems in networked environments in the advent of their dynamics.

The papers published in this section of the IFAC Annual Reviews in Control (ARC) have been selected and extended from the two tracks organised by the IFAC TC 5.3 "Enterprise Integration and Networking" held during the $14^{\text {th }}$ IFAC symposium on Information Control Problems in Manufacturing, Bucharest, Romania, May 23-15 2012. Most of the sessions of these tracks have been organised by volunteers, members of the IFAC TC 5.3, who have dedicated a big amount of their time to run successful sessions during the symposium. We would like to thank them for their involvement and dedicated effort to attract authors and to ensure their sound scientific contributions for the advances beyond the state-of-the-art in the research area of Enterprise Integration and Networking.

\section{THEORETICAL AND PRACTICAL CONTRIBUTIONS}

During the last years the research community has been developing solutions and publishing results contributing for the technical and scientific advancement of the Enterprise Integration and Networking research area. This work has been guided by identified major research challenges that have been worked out by the research community itself, assuring that research and development covers the main enterprise needs on integration and networking, and the solutions developed on the edge of the state-of-the-art are effective.

On this purpose, Panetto and Molina (2008) analysed, characterised and discussed on major research challenges for Enterprise Integration and Interoperability. Also, during the last years the Research Roadmap developed with the support of the European Commission Future Internet Enterprise Systems (FInES) cluster has been of reference for Enterprise Network research area.

The papers selected for this special section of ARC respond to these identified research challenges, providing theoretical and practical central contributions from research and development on the edge of the state of the art. Table 1 identifies the main contributions that each paper provide on the Research Challenges for Enterprise Integration and Interoperability characterised by Panetto and Molina (2008). The Grand Challenge 6 "Sustainability of Enterprise Interoperability" is introduced as a novel dare that the research community has to address to meet the requirements for adaptation of the enterprise systems and application in the advent of the networked environment dynamics, towards a complete lifecycle management of enterprise interoperability networked ecosystems at business, knowledge, applications and communications levels.

\subsection{Contributions in the business area}

One of the major problems identified today concerning Enterprise Integration and Networking is related with the sustainability of the interoperable global environment once an integrated solution is achieved. With time, the applications and processes change, new parties join or leave the network, and this dynamic creates interoperability breakdown, disabling the already established global seamless operating environment. One of the principal reasons for this happening is that solutions are typically developed unilaterally, without a thoughtful joint analysis and decision, which makes difficult to resume the globally interoperable stage in the advent of individual or networked environment changes.

The frequent business changes disturb the interoperability links between the enterprises, leading to periods of adaptation where business operation is reduced or even not possible. The urge to rapidly regain interoperability often leads to unfounded, poorly-chosen solutions, which lead to inefficiency and deep rework. Thus, to have a strong interoperable environment requires performing constant, periodic 
maintenance operations in order to adapt enterprises to their surrounding ecosystem. This leads to the need for negotiations towards the achievement of Sustainable Enterprise Interoperability (SEI) that should be supported by a framework that promotes continuous improvement and adaptation towards the management of interoperability on enterprise systems, and which has negotiations as a core mechanism to handle inconsistencies and solutions for the detected interoperability problems. Following this approach, enterprises shall become more adaptable to changes and external factors, consequently developing resilient and efficient interactions with its supply chain.

However, interoperability between the involved parties in a negotiation is often not reached or maintained due to failure in adapting to new requirements, parties or conditions. Cretan et al. (2012) propose NEGOSEIO, a Collaborative Framework for Sustainable Enterprise Interoperability, to solve interoperability discrepancies in enterprise interactions, allowing a sustainable interoperability networking environment along its life cycle. With NEGOSEIO, SEI is possible when constant and periodic monitoring and maintenance is performed to the interoperable environment, whenever negotiations are essential on complex business environments to reduce the time where there is no operation, and improve resource and time management. Integration of formal procedures for modelling, storing and documenting the negotiation activities allows an optimised analysis of the alternative solutions and by adding the analysis of lessons-learned on past activities leads to maximised negotiation results, stronger negotiation capabilities and relationships. The use of the NEGOSEIO adaptive platform, supported by a proper architecture and methodology that includes a formal negotiation model, results in a sustainable instrument for interoperability maintenance along the enterprise networked ecosystem life cycle. This favours its maintenance across time, enabling to reach and interoperate with more parties which lead to new business opportunities and to stronger and improved interactions.

Actually, interoperability is considered a challenge conditioning the success of the enterprises deployment. The deployment of new processes in a company results from a strategic decision, as it consists in the progressive modification of existing activities or in the addition of new ones considered as required and relevant to the business strategy. Hence, the introduction of new processes in an enterprise is a strategic decision that cannot fail considering the risks it implies, which are better the chances of success for the deployment whenever it is maximized the interoperability of entities involved or impacted by it. With such interoperability established, the risk of process rejection and resistance to change will be reduced, the transition period from deployment to a normal execution will be shortened, the more entities are interoperable the more the execution time of process activities is reduced, and a better interoperability of entities usually implies better business satisfaction since they will spend less time in non-added value activities for seamless operation.

To improve the level of interoperability of their systems and applications, enterprises must have a suitable methodology to evaluate it, also appropriate for the assessment of the interoperability of the networked enterprise environment where they will operate. Cornu et al. (2012) propose an Interoperability Assessment Methodology (IAM) applicable to both organizations and single resources, to guide the selection and allocation of entities that are considered to take part in the new processes to be deployed, to localize interoperability difficulties and propose corrective actions, and to monitor the evolution of the interoperability of entities to ensure that corrective actions are effective and efficient. It characterises several interoperability assessment types and the entities to be assessed described in an Interoperability Assessment Matrix, conducting to the identification of the needs to be met by interoperability assessment solutions and tools.

IAM is supported by a meta-model that enables the complete management of the methodology process and procedures along its implementation, having the assessment methods mathematically formalised. The methodology enables an assessment before, during or after the beginning of business collaboration, and with a known or unknown partner. It is designed to be used by enterprises with the support of a computational tool, and usable for prevention, detection and correction of interoperability problems. IAM can be used as a basis to improve the interoperability of enterprises' resources, even regardless of a deployment effort, reducing the collaboration difficulties and increasing the global reactivity of the enterprises. 


\subsection{Contributions in the knowledge area}

For an effective change of enterprise systems and applications, when operating individually or integrated in a networked environment, there is the need for a broad and seamless access to the information about the actual and demanded business scenarios. Therefore, it is needed to access to integrated information that is usually heterogeneous and stored in different data sources, causing semantics losses and an obstacle for the complete understanding of the relationships between the available information. In order to deal with these issues, a reference business ontology designed for information interoperability should be developed. Then, using an Ontology-Based System (OBS) with formalized knowledge for supporting the design of products and related manufacturing processes, would enable to exploit knowledge about the business in general, like product, processes, resources and sustainable manufacturing for proposing design and manufacturing process changes. In such reference ontology, concepts, processes and resources are associated to functions and enterprise knowledge, resulting in a knowledge-based system that, simulating a business enterprise expert, is able to automatically identify change opportunities and to propose alternatives on the basis of the existing business scenario.

Giovannini et al. (2012) propose a semantic model in an OBS to formalize and relate required concepts for making a knowledge-based system (KBS) able to support the identification of change opportunities and to support decision makers with the appropriate knowledge for the business and technological solutions deployment. In this proposal, a formal method equipped with a tool able to identify sustainable opportunities in product and manufacturing processes design is presented, including an extension of a product-centric ontology based on a functional vision. Concepts about all knowledge needed for this task are described and required information from heterogeneous sources to common semantics is aligned. However, some critical points are identified in this proposal, e.g., the definition of functions and the formalisation of business rules.

Nevertheless, to infer knowledge about functions and business solutions, it is needed a high level of detail for function effects definition and in product, processes and resources descriptions. Also, if it is required deployment of the ontology on more production sites, differences in the formalization of business constraints should be found. For instance, different applied standards lead to different interpretation of the business criteria, and thus an evolving ontology should be considered to manage the dynamics of this variability. Indeed, current alternative solutions are adapted to information but they ignore dynamics of enterprise business processes. The inference engine considers as feasible a solution that respects all functional constraints, but constraints of a local production site can limit its applicability. A noteworthy perspective should be the analysis of how the sustainability of solutions can be fitted to enterprises processes, to make possible a more effective and long term support for the deployment. This cannot be only an adaptation, but it requires strategies to enhance solutions effects on the basis of the knowledge about business processes, with output information seamlessly mapped directly with semantically enriched enterprises databases for further reduction of the deployment time.

The collaborative activity is synchronized and coordinated through a set of collaborative processes to build and maintain a shared representation of a business situation among all stakeholders, where the success of the collaboration process is linked with the share of knowledge between these actors to ensure a common understanding of the business scenario. However, the shared knowledge is composed of set of fragments that are created by various actors according to their expertise domain, and it is important to consider the consistency and common understanding of the interconnected data and information coming from different activities and managed by different and heterogeneous information systems. Thus, the knowledge sharing is constructed according to a set of cognitive and organizational processes, from the aggregation of different data and information defined in separate repositories, organized according to specific models and manipulated by different tools and actors.

To improve the consistency of the whole system design and the related data and information, knowledge crossing expertise must be tracked and formalized regarding a shared reference. Therefore, instead of defining a large reference models to which each expert refers to, a collaborative model should be defined enabling to seamless connect and integrate the data from each expert model. Belkadi et al. (2012) propose a new meta-model based on a Model-Driven Engineering approach to manage the integration of heterogeneous experts' knowledge models in a collaborative process. The structure of the proposed knowledge meta-model is defined taking into account the complexity of knowledge definition and the properties of its components. This meta-model is split in a meta-model of data and in a collaboration meta-model, to represent the distinction between the core concepts of knowledge and other elements 
serving to represent the relation between these concepts, and between concepts of heterogeneous experts' models. This meta-modelling approach supports the integration of multi-knowledge models and guarantees data consistency in context of collaborative work. Its application consists of two steps, i.e., the mapping between the generic concepts of the knowledge meta-model and their related concepts in specific knowledge model, and the instantiation of the generic model in coherence with the mapping results.

An application of knowledge management in enterprise integration and networking is described in the case study presented by Zdravkovic et al. (2012) that uses a Semantic Interoperability Framework (SIF) for custom orthopaedic implants manufacturing. Actually, the success of the orthopaedic predictive, preventive, diagnostic and therapeutic activities depends on the variety of factors, such as the availability of data about patient's condition, physician's knowledge and experience and availability of tangible resources (e.g., instruments, devices, fixtures, implants, software, etc.). However, surgeons are often not able to perform those activities efficiently because they are required right when decisions are to be made fast, and based on complete and updated information on the patient's condition. Those decisions assume the selection of appropriate actions, and are typically facilitated by the Enterprise Information Systems (EIS), which reflects two important issues that are identified in the daily practice in orthopaedics surgery, i.e., information interoperability and manufacturing of highly customized products.

The main features of the proposed infrastructure for custom orthopaedic implants manufacturing is based on the SIF, where the product infrastructure is represented by Description Logics (i.e., OWL based ontologies). The Enterprise Information Systems in the Enterprise Networked ecosystem is semantically interoperable, with each of the systems introduced into the collaborative network by its local ontology and using a central reference ontology with defined mappings between the concepts of different local ontologies. These mappings are stored in a form of SWRL (Semantic Web Rule Language) rules. The reference ontology then becomes a single point of access to the integrated ontology framework, and it is used to execute semantic queries within this framework. The local ontologies are explicit conceptualizations of the Enterprise Information Systems, generated by the method which performs the semantics analysis of the systems' database schema and transforms it into OWL ontology. The main components of the implementation architecture are Interoperability Service Utilities, which facilitate the registration of a local ontology represented by some domain or application ontology, the transformation of a local ontology from the sources of the implicit semantics, the semantic querying, the semantic reconciliation and the knowledge reasoning. Shared functions of the interoperable infrastructure are realized by the specific semantic applications, which formalize task-solving knowledge and use semantic queries to get necessary information from the integrated ontology framework, executed on the central ontology.

\subsection{Contributions in the application and standardisation areas}

Networked enterprises are required to continuously evolve so as to adequately respond to a dynamic, global and very competitive business environment, and this continuous change requirement affects the capacity of the enterprise to effectively interoperate internally and externally. Adding to this problem, the standards typically used as pillars for enterprise and network management and (inter)operation are themselves subject to continuous change and often bring their own interoperability, inconsistency and overlap problems. Thus, it is essential that such concerns are identified and addressed in a sustainable manner, taking into account the life cycles of the integrated networked environment and of all entities involved as their interoperability capabilities and requirements change along their lives. Standards interoperability is also an essential factor promoting ease of standalone or combined use, user acceptance and efficient administration and maintenance. As standards continuously evolve, adequate interoperability must be achieved but also maintained during their lives. Sustainable interoperability of standards involves a multitude of interdependent aspects and levels, reaching from infrastructure all the way to the organisational culture and background of the custodian work groups.

However, a large majority of the standards involve the work and consensus of experts that are typically volunteering their time and resources in the process, and the use of standards is regulated or mandated by government and private organisations and agencies. This means that most of the time companies must abide by the standards specified by the clients and in legal documents. Also, the problems of glossary consistency and overlap leading to low interoperability have been long recognised in the standards community. As a result, there have been occasional attempts to harmonise standards, with varying degrees of success. Typically, these attempts were lengthy and expensive endeavours restricted to a few 
standards. Actually, in the absence of a reference framework commonly agreed upon that can be used to reach common ground, harmonisation results in a political and lobbying exercise as all standards involved may be subjected to changes and naturally the custodian working groups of each participating standard are standing by their own work.

Noran (2012) focuses on interoperability issues specific to standards and proposes a novel way forward based on principles tested in previous case studies combining elements from the Enterprise Interoperability, Architecture and Integration, Collaborative Networks and Artificial Intelligence bodies of knowledge. Based on the previous results and on-going research work, it is proposed a more structured and widely applicable approach to achieve sustainable consistency, redundancy elimination and interoperability. The creation of a common workplace driven by an intelligent structured repository allows a starting point to effectively address the problems identified, like interoperability-relevant elements (e.g., aspects, barriers) can be sourced by mapping and decomposing the mainstream interoperability frameworks (IFs) in respect to a reference framework. By a similar process, the repository is populated with elements sourced from standards, and rules can then be added to enable querying the repository and thus transforming it into a knowledge base. This proposal results in a system that addresses the above-mentioned aspects by combining concepts drawing from the Interoperability, Enterprise Integration, Collaborative Networks and Artificial Intelligence bodies of knowledge.

The transformation between formal models can be implemented to tackle this challenge, using modelmorphism to describe the transformations and meta-modelling to support the implementation and execution of tools for automatic model transformations. Soliman et al. (2012) propose the adoption of this methodology in a set of transformation rules defined for the automatic transformation of IEC 61131-3 function block based safety applications to UPPAAL timed automata models. These models are next used for the verification of the safety application, where both the source and the target domain models have been formally defined and these definitions are used for the formal definition of the transformation rules. Based on this methodology a tool for model transformation was developed using Java, and employed in various safety applications proving the efficiency of the transformation process.

\section{TRENDS AND CONCLUSIONS}

Panetto and Molina (2008) summarized the need for Enterprise Integration and Interoperability in Manufacturing Systems. In this special issue, this work was revised to reflect the actual trends and state of the art, and a new Grand Challenge was identified, i.e., Sustainability of Enterprise Interoperability. Thus, an additional area has been included in this contribution to complete all relevant challenges faced by this area of research, namely, "Sustainability of Enterprise interoperability", and now six Grand Challenges are classified according to the following areas(Table 1):

1. Collaborative Networked Organizations

2. Enterprise Modelling and Reference Models

3. Enterprise and Processes Models Interoperability

4. Validation, Verification, Qualification and Accreditation of Enterprise Models

5. Model Reuse and Repositories

6. Sustainability of Enterprise interoperability

During last years, significant discussions and contributions have been published on these areas, where trends to be faced in order to tackle 2020 Manufacturing challenges and successfully design and creation of the true concept of "Networked Enterprise" ecosystem (Romero et al., 2009). (Panetto, 2007) classified and developed the frameworks for analysing interoperability issues and the degree of interoperability/integration desired in a joint family of systems or units, driven by the underlying operational level of those systems. Jardim-Goncalves et al. (2012) elaborated a comprehensive analysis of the Systematisation of Interoperability Body of Knowledge as the basis for the foundation for Enterprise Interoperability as a science. The analysis about Interoperability Frameworks, Interoperability Theories and Interoperability Models are discussed in the presence of the state of the art, and it offers interesting insights regarding the current state of play on the systematization of Interoperability Body of Knowledge providing relevant perspectives about directions for future research and development in the field. The following are a summary of the trends that the authors have identified: 
- $\quad$ The need for design patterns and model-based components available as (commercial) building blocks to design, build, and reengineer large scale systems not only to support single Enterprise Integration but also helping at formally assessing interoperability barriers (Yahia et al., 2012) in Collaborative Networked Organizations. Also, the value proposition on interoperability has been considered a focus for the targeting solution in the domain of Enterprise Integration and Networking (Grilo et al., 2010)

- The creation of a standard, user-oriented, interface in the form of a unified enterprise modelling language (UEML) based on the previous consensus to be available on all commercial modelling tools (Panetto et al., 2004)( Anaya et al., 2010).

- There are real enterprise modelling and simulation tools commercially available taking into account function, information, resource, organization, and financial aspects of an enterprise including human aspects, exception handling, and process coordination. Simulation tools need to be configurable, distributed, agent-based simulation tools (Hall and Harmon, 2005).

- The application of reference models has been studied to have more experiences in the creation of a reference model for enterprise integration and networking towards the realization of Future Internet Enterprise Systems (FInES) (Jardim-Goncalves et al., 2012). Concerning Interoperability Frameworks, it is undisputable that there is maturity around in the current body of knowledge. Several authors have developed Enterprise and Government Interoperability specific frameworks, with more or less layers and variables, but overall most frameworks are structured similarly, considering the technological, business and organizational perspectives.

- $\quad$ Reference architectures and methodologies, as MDA (Model driven Architecture) (Frankel, 2003) and SOA (Service Oriented architecture) (Bell, 2008), have been applied and used as a basis for the development of solution to support Enterprise Integration and Networking (Jardim-Goncalves et al., 2006). Services and Servitization, are concepts that actually are considered pillar for the development of seamless solutions, contributing for easier and agile answers for many of the main interoperability problems identified.

- There are commercially available integration platforms and integrating infrastructures (in the form of packages of computer services) for plug-and-play solutions (Daigneau, 2012). ARCON is an example of an architecture for collaborative networks (Camarinha-Matos et al. 2008).

- A community with knowledge organisation based on ontologies will enable an increase in the computational intelligence of its information systems (Sarraipa et al., 2010). However, due to the worldwide diversity of communities, a high number of knowledge representation elements, which are not semantically coincident, have appeared representing the same segment of reality, becoming a barrier to business communications. As future trend, it is foreseen the need for a methodology to support the development of a common reference ontology for a group of organisations sharing the same business domain. This methodology should be based on the mediator ontology (MO) concept, which assists the semantic transformations among each enterprise's ontology and the referential one. The MO enables each organisation to keep its own terminology, glossary and ontological structures, while providing seamless communication and interaction with the others.

- The sustainability of the Enterprise Integration and Networking environments is a high-impact productivity factor both within the private and the public sector, affecting the overall quality, yield time and cost of transactions, as well as the design of manufacturing operations or digital public services. Future research in this area has to embrace the rationale and analysis of the results of the state of the art in this area, focusing on novel strategies, methods and tools to maintain and sustain the interoperability of enterprise systems in networked environments as they evolve with their environments.

Nevertheless, although there is a clearly established framework for enterprise interoperability to identify barriers, problems, issues and solutions to let enterprise interoperate in a structured and unambiguous way, the future trends in enterprise integration and enterprise modelling requires the creation of model-driven architectures that will allow users to design, implement and execute Total Interoperable Enterprise systems.

Regarding future work on this area, it is recommend that researchers abstain from creating more diversity in terms of approaches since the problem space is overall confined, and rather focus on the opportunity to further refine the details along with providing more clear detailed analysis about the interrelationships between the various variables on the different layers and perspectives and aim at delivering a systematized cause-effect framework. 


\section{ACKNOWLEDGEMENT}

It has been a great pleasure to work with the international committee members of this special issue who played a valuable role in reviewing the submitted papers and contributed for the improving of the selected papers. We thank all of them for their dedication and interest. We take this opportunity to thank all authors for their contributions to this special section of the journal.

\section{REFERENCES}

Anaya, V., Berio, G., Harzallah, M., Heymans, P., Matulevičius, R., Opdahl, A.L., Panetto, H., Verdecho, M.J (2010). The Unified Enterprise Modelling Language-Overview and further work. Computers in Industry, 61(2), 99-111.

Belkadi, F., Notin, A., Dremont, N., and Troussier N. (2012). A meta-modelling framework for knowledge consistency in collaborative design. Annual Reviews in Control, 36(2)

Bell, M. (2008). Service-Oriented Modeling (SOA): Service Analysis, Design, and Architecture. Wiley publishing

Camarinha-Matos, L.M.; Afsarmanesh, H., Galeano, N. and Molina, A. (2008). Collaborative Networked Organizations - Concepts and practice in Manufacturing Enterprises, Computers \& Industrial Engineering, December, DOI: 10.1016/j.cie.2008.11.024, The Netherlands: Elsevier Science, Pergamon Publisher, ISSN: 0360-8352,

Cornu, C., Chapurlat, V., Quiot, J.M., and Irigoin, F. (2012). Customizable interoperability assessment methodology to support technical processes deployment in large companies. Annual Reviews in Control, 36(2)

Cretan, A., Coutinho, C., Bratu, B., and Jardim-Goncalves, R. (2012). NEGOSEIO: A Framework for Negotiations toward Sustainable Enterprise Interoperability. Annual Reviews in Control, 36(2)

Daigneau, R. (2012). Service Design Patterns: Fundamental Design Solutions for SOAP/WSDL and RESTful Web Services. Addison-Wesley, ISBN-10: 032154420X. 352 pages.

Frankel, D.S. (2003). Model Driven Architecture: Applying MDA to Enterprise Computing. Wiley publishing

Giovannini, A., Aubry, A., Panetto, H., Dassisti, M., and El Haouzi H. (2012). Ontology-Based System for supporting Manufacturing Sustainability. Annual Reviews in Control, 36(2)

Grilo A. and Jardim-Goncalves, R. (2010) Value proposition on interoperability of BIM and collaborative working environments, Automation in Construction, vol. 19, no. 5, pp. 522-530, Aug. 2010.

Hall, C. and Harmon, P. (2005). The 2005 Enterprise Architecture, Process Modeling \& Simulation Tools Report. BP Trends. Available: http://mhcnet.com/whitepapers_presentations/2005\%20Process\%20Trends\%20\%28040306\%29.pdf

Jardim-Goncalves, R., Grilo, A. and Steiger-Garcao, A. (2006) Challenging the interoperability between computers in industry with MDA and SOA, Computers in Industry, vol. 57, no. 8-9, pp. 679689, Dec. 2006

Jardim-Goncalves, R., Grilo, A., Agostinho, C., Lampathaki, F., and Charalabidis, Y. (2012) Systematisation of Interoperability Body of Knowledge: the foundation for Enterprise Interoperability as a science, Enterprise Information Systems, vol. 6, no. 3, pp. 1-26, 2012

Molina A., Chen D., Panetto H., Vernadat F., Whitman L. (2005), Enterprise Integration and Networking: Issues, Trends and Vision, in Knowledge Sharing in the Integrated Enterprise, IFIP International 
Federation for Information Processing, Volume 183/2005, 303-313, DOI: 10.1007/0-387-2976692

Molina A., Panetto H., Chen D., Whitman L., Chapurlat V., Vernadat F.B., (2007). Enterprise Integration and Networking: Challenges and Trends. Studies in Informatics and Control. 16/4. 353-368. December 2007, Informatics and Control Publications. ISSN 1220-1766

Noran, O. (2012). Achieving a Sustainable Interoperability of Standards. Annual Reviews in Control, $36(2)$

Panetto H. (2007). Towards a Classification Framework for Interoperability of Enterprise Applications. International Journal of CIM, 20/8, 727-740, Taylor \& Francis, December, ISSN 0951-192X.

Panetto, H., and Molina, A. (2008). Enterprise Integration and Interoperability in Manufacturing Systems: trends and issues. Computers in Industry, 59 (7) 641-646

Panetto, H., Berio, G., Benali, K., Boudjlida, N., Petit, M. (2004). A Unified Enterprise Modeling Language for enhanced interoperability of Enterprise Models. Preprints of the 11th IFAC INCOM2004 Symposium, April 5-7, Salvador, Brazil

Romero, D., Rabelo, R., Hincapie, M., Molina, A. (2009), Next Generation Manufacturing Systems and the Virtual Enterprise, 13th IFAC Symposium on Information Control Problems in Manufacturing, Moscow, Russia, June 3 - 5, 2009

Sarraipa, J., Jardim-Goncalves, R. and Steiger-Garcao, A. (2010) MENTOR: an enabler for interoperable intelligent systems, International Journal of General Systems, vol. 39, no. 5, pp. 557-573, Jul. 2010

Soliman, D., Thramboulidis, K., and Frey G. (2012). Transformation of Function Block Diagrams to UPPAAL Timed: Automata for the Verification of Safety Applications. Annual Reviews in Control, 36(2)

Yahia, E., Aubry, A., Panetto, H. (2012). Formal measures for semantic interoperability assessment in cooperative enterprise information systems. Computers in Industry, 63(5), 443-457.

Zdravkovic, M., Stojković, M., Mišić, D., and Trajanović M. (2012). A case of using the Semantic Interoperability Framework for custom orthopaedic implants manufacturing. Annual Reviews in Control, 36(2) 
Table 1. Contributions to the Research Challenges for Enterprise Integration and Interoperability (updated from Panetto and Molina, 2008)

\begin{tabular}{|c|c|c|c|c|c|}
\hline \multirow[b]{2}{*}{ CHALLENGES } & \multirow[b]{2}{*}{ CONTRIBUTING PAPER } & \multicolumn{4}{|c|}{ ENTERPRISE INTEGRATION AND INTEROPERABILITY AREA } \\
\hline & & BUSINESS & KNOWLEDGE & APPLICATIONS & COMMUNICATIONS (ICT) \\
\hline $\begin{array}{l}\text { Grand Challenge } 1 . \\
\text { Collaborative Networked } \\
\text { Organizations (CNOs) }\end{array}$ & $\begin{array}{ll}\text { - } & \text { (Belkadi et al., 2012) } \\
\text { - } \quad \text { (Cretan et al., 2012) } & \text { (Zdravkovic et al., 2012) }\end{array}$ & $\begin{array}{l}\text { - Business and strategy models } \\
\text { - Reference Models of CNOs } \\
\text { collaboration networks }\end{array}$ & $\begin{array}{l}\text { - Knowledge about business processes } \\
\text { and operations in CNOs } \\
\text { Knowledge about core competencies } \\
\text { (resources based view) } \\
\text { Sharing principles and operation rules }\end{array}$ & $\begin{array}{l}\text { - Collaborative software solutions } \\
\text { Software to simulate operation to } \\
\text { see parallelism and concurrency } \\
\text { Tools for monitoring and control } \\
\text { of parallelism and concurrency }\end{array}$ & $\begin{array}{l}\text { - Reliable communication } \\
\text { networks } \\
\text { - Broadband } \\
\text { - Wireless applications }\end{array}$ \\
\hline $\begin{array}{l}\text { Grand Challenge } 2 . \\
\text { Enterprise Modelling and } \\
\text { Reference Models }\end{array}$ & $\begin{array}{ll}\text { - } & \text { (Belkadi et al., 2012) } \\
\text { - } \quad \text { (Netan et al., 2012) } & \text { (Noran 2012) }\end{array}$ & $\begin{array}{l}\text { - Enterprise measurement } \\
\text { systems (e.g. Balanced Score Card) } \\
\text { - Compensation systems based } \\
\text { on enterprise performance } \\
\text { measures } \\
\cdot \quad \text { Model Driven Architectures }\end{array}$ & $\begin{array}{l}\text { - Description of Skills, Core } \\
\text { Competencies, Organization roles and } \\
\text { Knowledge assets } \\
\text { On line resources availability and } \\
\text { capacity } \\
\quad \text { Balanced automatic vs. manual tasks }\end{array}$ & $\begin{array}{l}\text { Integration of Enterprise } \\
\text { Applications (ERP, MES, SCADA, } \\
\text { Factory Automation Systems) } \\
\text { Workflow management systems } \\
\text { (WfMS) } \\
\quad \quad \text { Computer Supported Cooperative } \\
\text { Work (CSCM) }\end{array}$ & $\begin{array}{l}\text { - Open platforms and } \\
\text { architectures } \\
\text { Human Computer Interaction } \\
\text { applications } \\
\text { Friendly User Interfaces }\end{array}$ \\
\hline $\begin{array}{l}\text { Grand Challenge } 3 . \\
\text { Enterprise and Processes } \\
\text { Models Interoperability }\end{array}$ & $\begin{array}{ll}\text { - } & \text { (Belkadi et al., 2012) } \\
\text { - } & \text { (Cretan et al., 2012) } \\
\text { - } & \text { (Ziovannini et al., 2012) } \\
& \text { (dravkovic et al., 2012) }\end{array}$ & $\begin{array}{l}\cdot \text { Integration of business } \\
\text { information } \\
\text { Networked enterprises } \\
\text { - Ontology mapping and } \\
\text { matching } \\
\text { Consistent enterprise-wide } \\
\text { decision-making structure }\end{array}$ & $\begin{array}{ll}\text { - } & \text { Interoperability of models } \\
\text { - } & \text { Standards (KIF, KQML) } \\
\text { - } & \text { Explicit } \text { Ontology } \\
\text { - } & \text { knowledgedge models } \\
& \end{array}$ & $\begin{array}{l}\text { - Standards and Interfaces } \\
\text { - Interoperable databases } \\
\text { systems } \\
\text { syar and Reconfigurable } \\
\text { solutionsonents based software } \\
\text { - } \quad \text { Simulation softwag out) }\end{array}$ & $\begin{array}{l}\text { - Standards } \\
\text { - Interfaces and mediators } \\
\text { - Interoperability }\end{array}$ \\
\hline $\begin{array}{l}\text { Grand Challenge } 4 . \\
\text { Validation, Verification, } \\
\text { Qualification and } \\
\text { Accreditation of } \\
\text { Enterprise Models }\end{array}$ & $\begin{array}{ll}- & \text { (Cretan et al. 2012) } \\
& \text { (Cornu et al., 2012) } \\
& \text { (Soliman et al., 2012) }\end{array}$ & $\begin{array}{l}\text { - Reference Models for } \\
\text { Validation, Verification and } \\
\text { Qualification and Accreditation } \\
\quad \text { New business models } \\
\text { evaluation for CNOs }\end{array}$ & $\begin{array}{l}\text { Ontology and formal modelling } \\
\text { - Model-based manufacturing and } \\
\text { control }\end{array}$ & $\begin{array}{l}\text { - Standards } \\
\text { - } \text { Models Formalization } \\
\text { - Safe systems }\end{array}$ & $\begin{array}{l}\text { - Interpretability } \\
\text { - Standards }\end{array}$ \\
\hline $\begin{array}{l}\text { Grand Challenge } 5 . \\
\text { Model Reuse and } \\
\text { Repositories }\end{array}$ & $\begin{array}{ll}\text { - } & \text { (Belkadi et al., 2012) } \\
\text { - } & \text { (Giovannini et al., 2012) } \\
\text { - } & \text { (Soran 2012) } \\
& \text { Soliman et al., 2012) }\end{array}$ & $\begin{array}{l}\text { - Distributed business } \\
\text { information systems } \\
\text { Unified Database Enterprise } \\
\text { Models }\end{array}$ & $\begin{array}{l}\text { Ontology and formal modelling } \\
\text { - Life Cycle Management Information } \\
\text { Models }\end{array}$ & $\begin{array}{l}\text { - Data Mining } \\
\text { - Databases and data warehousing } \\
\text { - Knowledge Based Systems }\end{array}$ & $\begin{array}{ll}\text { - } & \text { Standards } \\
\text { - } & \text { Interfaces } \\
\text { - } & \text { Interoperability }\end{array}$ \\
\hline $\begin{array}{l}\text { Grand Challenge } 6 . \\
\text { Sustainability of } \\
\text { Enterprise } \\
\text { interoperability }\end{array}$ & $\begin{array}{ll}\text { - } & \text { (Cretan et al., 2012) } \\
\text { - } \quad \text { (Giovannini et al., 2012) } & \text { (Noran 2012) }\end{array}$ & $\begin{array}{l}\text { - Life cycle management of } \\
\text { enterprise interoperability at } \\
\text { business level }\end{array}$ & $\begin{array}{l}\text { Life cycle management of enterprise } \\
\text { interoperability at knowledge level }\end{array}$ & $\begin{array}{l}\text { - Life cycle management of } \\
\text { enterprise interoperability at } \\
\text { applications level }\end{array}$ & $\begin{array}{l}\text { - Life cycle management of } \\
\text { enterprise interoperability at } \\
\text { communications level }\end{array}$ \\
\hline
\end{tabular}

